\title{
Palladium-Catalyzed Synthesis of Alkylidenecyclobutanes
}

Metal-Catalyzed

Asymmetric

Synthesis and

Stereoselective

Reactions
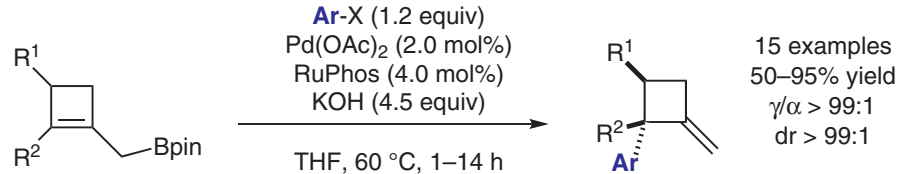

\section{Key words}

palladium catalysis

alkylidenecyclo-

butanes

$\gamma$-selective cross-

coupling

Selected examples:

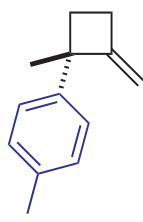

$\mathrm{X}=1$ $68 \%$ yield

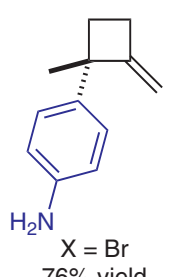

$76 \%$ yield
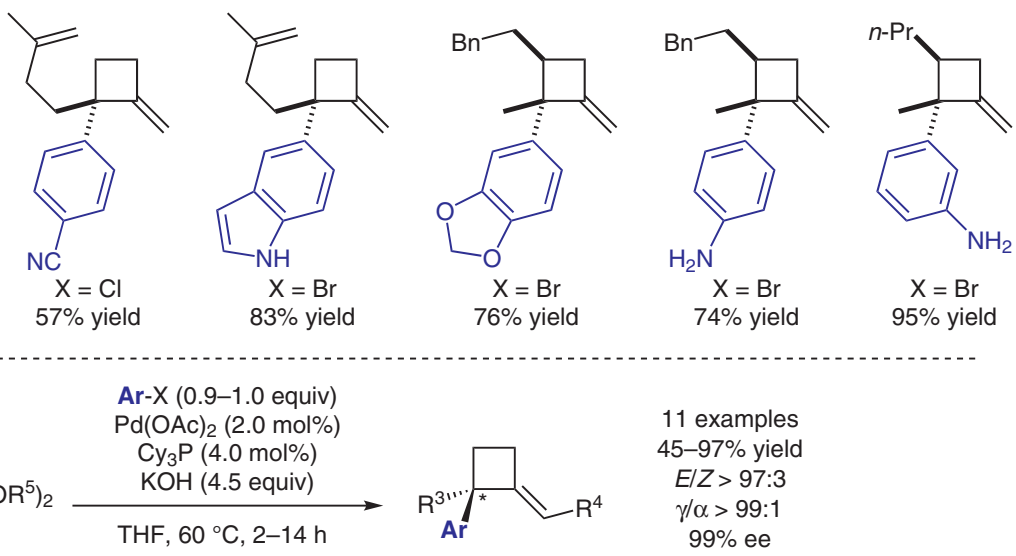

(99\% ee)

Selected examples:

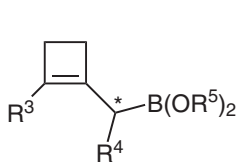

THF, $60{ }^{\circ} \mathrm{C}, 2-14 \mathrm{~h}$

$99 \%$ ee

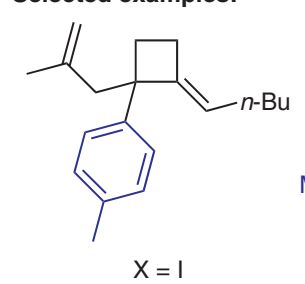

$81 \%$ yield

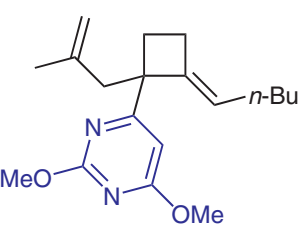

$\mathrm{X}=1$

$57 \%$ yield

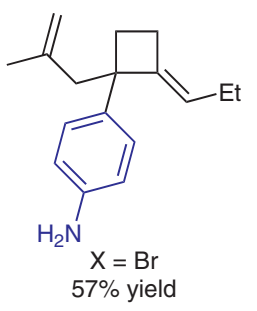

$57 \%$ yield
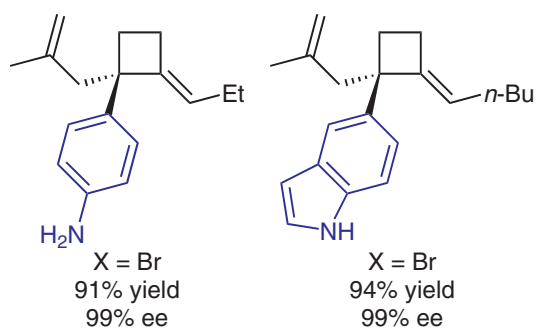

Significance: Alkylidenecyclobutanes are useful strained building blocks that can also be found in a number of natural compounds. In this work, the authors disclose the use of a $\gamma$-selective SuzukiMiyaura cross-coupling for the synthesis of this class of compounds containing a quaternary stereocenter.
Comment: Achiral cyclobutenylmethylboronic esters reacted with aryl halides in the presence of a palladium catalyst and potassium hydroxide. The corresponding products were obtained in moderate to excellent yields and essentially with perfect $\gamma$-selectivity. In the case of $\delta$-substituted substrates, high levels of diastereoselectivity were obtained. The use of (chiral) $\alpha$-substituted starting materials generated the corresponding products containing a trisubstituted double bond functionality in high stereoselectivity (and enantioselectivity).

SYNFACTS Contributors: Mark Lautens, Ivan Franzoni

Dol: 10.1055/s-0036-1591250; Reg-No.: L10017SF 